\title{
A Study of the Relationship Between Tutor's Personality and Teaching Effectiveness: Does Culture Make A Difference?
}

\author{
Bobbie Chan \\ Open University of Hong Kong
}

\begin{abstract}
Good tutoring requires appropriate interpersonal and pedagogical skills. Tutor personality is a major factor affecting how tutors communicate and deals with students, and yet it is a largely unexplored context of distance education. Using the Chinese Personality Assessment Inventory (CPAI)* this paper examines how the personality of tutors' affects their teaching effectiveness at a distance learning institution in Hong Kong. The results are compared to those reported by Chan (2001) in a similar study using the Myers-Briggs Type Indicator (MBTI). The results indicate that certain scales on the Chinese Tradition factor of the CPAI are significantly related to tutors' teaching performance, and that the MBTI could not subsume all the CPAI scales. Future research with the CPAI should explore whether this Chinese Tradition factor is unique to the Chinese culture or whether it comprises elements of a universal domain useful in understanding key interpersonal aspects of personality that have been absent from Western personality inventories.
\end{abstract}

Keyword: Chinese Assessment Inventory; tutor effectiveness; Myers-Briggs Type Indicator; personality; Chinese

\section{Introduction}

Special thanks to the developers of the Chinese Personality Assessment Inventory (CPAI): Prof. Fanny Cheung, Prof. Kwok Leung, Prof. Song Weizhen, Dr. Zhang Jianxin, and Zhang Jianping, who granted permission to use the instrument for this study.

Education involves human relationships; human interaction and distance education is no exception. During the past few decades, distance education has become an increasingly popular and widespread mode in response to adult learners' need for individualized and decentralized educational opportunities. Tutors and tutorials are important components within a distance education system. Distance education providers offer structured materials to guide students, enabling them flexibility in choosing where and when they study. Tutors act as a crucial link between the University and its students, and tutorials provide a great opportunity for face-to-face interaction between and amongst students and their tutors.

Tutors are content experts who must cope with heterogeneous student group(s). Distance learners are mostly working adults and tend to be more intrinsically motivated than their younger counterparts (Harper and Kember, 1986). Distance learners also tend to rely 
Chan - A Study of the Relationship Between Tutor's Personality and Teaching Effectiveness

more on a deep learning approach than school-leavers, who mainly rely on rote learning (Watkins and Hattie, 1981; Watkins, 1983). As Beaudoin (1990) states, tutors engaged in distance education must be adept at facilitating students' learning by paying particular attention to process, rather than their work being confined to selecting and sharing content. Building on previous research findings that the environment is, to a large extent, influenced by the teacher (e.g., Deci, Schwartz, Sheinman, and Ryan, 1981a; Deci, Nezlek, and Sheinman, 1981b), this paper defines an effective tutor as the one who uses autonomy-supportive strategies instead of controlling strategies to assist students to become independent learners.

Good tutoring requires a repertoire of appropriate interpersonal and pedagogical skills. Tutor personality is a major factor affecting how they communicate and deal with their students; however, it is a largely unexplored context of distance education. Using the Myers-Briggs Type Indicator (MBTI), Chan (2001) investigates the impact of personality types of tutors on their teaching effectiveness at a distance learning institution in Hong Kong. The results revealed that tutors characterized by a high degree of extraversion were more effective in the classroom environment. Yet no statistically significant difference was found with respect to other personality dimensions. The MBTI is probably the most widely used personality measure in occupational and counseling psychology. However, because it was developed in the West, most studies using this measure have been restricted to North American contexts. Whilst the use of MBTI did not yield particularly significant result in Chan (2001), this paper replicates that study using the Chinese Personality Assessment Inventory (CPAI), which consists of personality constructs of specific interest to people of Chinese culture - personality constructs not covered in most of the translated personality inventories. The aim of this paper is to explore whether a culturally specific instrument will be a more comprehensive measure, one that works to reveal particular distinctive factors in the relevant culture.

\section{Tutor's Roles, Personality, and Classroom Environment}

The concept of self-learning is heavily emphasized in distance education. Tutors are leaders, facilitators, and coaches of their tutorials (Barrows, 1992). Aspects of tutors' role in tutorials encompass answering queries, clarifying points, diagnosing misconceptions, providing alternative explanations, assisting students to relate material to their individual situations, and helping with the application and practice of principles. Another important aspect of tutors' role is that of assisting students to become independent learners. With tutor guidance, students can be encouraged to dig deeper and to explore the unknown to support their ideas, thoughts, comments, and feelings. How tutors teach is critical to learning, and how they create and foster learning environments that promote creative thinking and problem-solving skills in students is of vital importance. For example, tutors' use of diverse methods and strategies in presentation of subject content, in leading discussions and debates, and in encouraging small group interactions, helps to nurture student curiosity. These approaches encourage students to study issues from contrasting views. An innovative tutor can create ways to build mutual successes between themselves and students. Therefore tutors must be able to tolerate new ideas and differences of opinion. They must also be willing to venture fresh avenues of teaching and learning, and consider what triggers, inspires, and motivates students' intellectual and individual interests (Barrows, 1992).

Tonelson (1981) suggests that teacher personality can affect student learning outcomes via the psychological environment of the classroom. Research indicates that a teacher's motivating style is an important educational construct (Deci et al., 1981a; Ryan and Grolnick, 1986) because it affects students' developmental and academic outcomes (Deci 
and Ryan, 1987; Deci, Vallerand, Pelletier, and Ryan, 1991; Reeve, 1996). Yet how do teachers motivate students in their studies? A number of researchers (e.g., Deci et al., 1981a; Reeve, 1998; Ryan and Grolnick, 1986) suggest that teachers motivate students using interpersonal styles that range from highly controlling to highly autonomous and supportive. Highly controlling teachers use rewards, threats, deadlines, etc., to "control" student learning outcomes. The teacher's goal is to control students' goals and behaviours toward a prescribed end. On the other hand, relatively autonomy/ supportive teachers encourage students to pursue self-determined agendas, and foster and support students' initiatives and intrinsic motivation (Deci et al., 1981b). Their goal, in this instance, is to strengthen students' autonomous self-regulation.

In order to become independent and to develop the ability to solve problems and to be able to learn on their own, distance learners must not be put into passive learning situations where tutors determine what should be learned, to what depth, and in what sequence (Barrows, 1992). Instead, students must practice dealing with problems and learn to identify what they need to learn. To facilitate student independence and foster students' critical thinking and self-directed continuous learning, tutors should guide students in their thinking, stimulating them to be reflective, carefully reasoning thinkers not impulsive ones. Students should become independent problem solvers and selfdirected learners. In this regard, effective tutors in a distance education system should adopt autonomy-supportive strategies, which seem to be more appropriate than controlling strategies in teaching distance learners.

Compared to students who have been taught by controlling teachers, students with autonomy/ supportive teachers report greater perceived academic competence (Deci et al., 1981a; Ryan and Grolnick, 1986), higher academic intrinsic motivation (Deci et al., 1981), greater creativity (Amabile, 1979; Koestner, Ryan, Bernieri, and Holt, 1984), more mastery motivation (Ryan and Grolnick, 1986), preference for optimal challenge (Pittman, Emery, and Boggiano, 1982; Shapira, 1976), greater conceptual understanding (Benware and Deci, 1984; Flink, Boggiano, Main, Barrett, and Katz, 1992; Boggiano, Flink, Shields, Seelbach, and Barett, 1993; Grolnick and Ryan, 1987), positive emotionality (Patrick, Skinner, and Connell, 1993; Ryan and Connell, 1989; Williams, Weiner, Markakis, Reeve, and Deci, 1994), lower dropout rates (Vallerand, Fortier, and Guay, 1997), as well as higher academic performance (Boggiano et al., 1993) and achievement (deCharms, 1976; Flink et al., 1992). Indeed, Kagan and Grandgenett (1987) observe that a sizeable body of empirical research reveals consistent relationships between teachers' personality traits and their preferred instructional style. For example, Lorentz and Coker (1977) found significant relationships between teachers' scores on the MBTI and the behaviour of their students, concluding that teacher personality influenced the way in which students reacted in class. Using the MBTI and another instrument, Fisher and Kent (1998) found significant associations between teacher personality type and perceptions of classroom environment. For example, both students and teachers perceived greater student cohesiveness in classes taught by extraverted teachers.

Whilst these studies are related to teaching and learning in high schools, personality characteristics and classroom management behaviours seem to be related in particular patterns. Barrett (1991) shows that certain personality types have a positive relationship to a number of important teaching effectiveness competencies and that certain styles have greater ease or difficulty in achieving high effectiveness scores. Hamza and Nash's (1996) study shows that teachers of particular character traits are better able to foster a learning environment that promotes creative thinking and problem solving skills. 
Chan - A Study of the Relationship Between Tutor's Personality and Teaching Effectiveness

\section{The Cross-Cultural Challenge}

Historically the study of personality, groups, leadership, and other topics of organisational behaviour have largely been a North American endeavour and for years researchers have asked whether or not particular personality traits are found universally. Meanwhile, the use of personality assessments were imported from the West to Asia in the 20th century. However, there has been severe criticism of validity and reliability problems associated with a blind importation of Western instruments into non-Western countries (e.g., Cheung, 1996).

Bond (2000) cites three reasons that the importation of personality theories from the US to other countries should be rejected. First, the measure and the relevant theory will affect the development of a local theory. Second, the receiving culture may not have the necessary support for translating and interpreting such a test and extending its theories into their new cultural territory. Consequently, the imported constructs and measures may not be as appropriate as indigenous instruments or theory in predicting key outcomes. Third, the imported instrument and its theory may not fully encompass the local reality associated with a concept.

A challenge for cross-cultural personality assessment is to construct an inventory suited to the local needs while retaining the standards of validity and reliability expected of established assessment instruments (Cheung, 1996). Often people fail to address the issue of the omission of important culture-specific constructs that are indigenous to a particular culture (Church, 1987). If the purpose of a personality inventory is to provide a reliable and valid assessment instrument within a particular culture rather than to investigate cultural universals, then we need an inventory that includes the major culture-specific personality domains in addition to the culture-comparable personality constructs. Leung and Zhang (1995), after a review of various viewpoints, conclude that indigenous research and theorizing, as well as research that integrates different cultural perspectives, are crucial to the establishment of more useful and universal psychological theories.

\section{Chinese Personality Assessment Inventory (CPAI)}

In the early 1990s, Cheung and her colleagues began developing a Chinese Personality Assessment Inventory using self-referent statements about beliefs, attitudes, values, and behaviours to describe personality for both normal and diagnostic assessment (Cheung, 1996).

The personality constructs included in the CPAI were derived from groups of personality adjectives or descriptions reflecting daily experiences. The sources of these adjectives include a selection of popular contemporary Chinese novels, books on Chinese proverbs, informal surveys to obtain statements of self-descriptions by people in the street, and statements of other-descriptions by professionals, managers, teachers, and health workers, as well as the research literature on personality of the Chinese people (Cheung et al., 1998, p.4).

The CPAI is an extensive personality questionnaire developed by indigenous psychologists in a deliberate attempt to include culture-specific indigenous content. They have taken special care to include "the emic personality characteristics that were deemed to be of specific interest to the Chinese culture, but are not covered in imported personality inventories” (Cheung et al., 1998). The final version of the CPAI consists of 
524 items, comprising 22 personality scales, 12 clinical scales, and three validity scales or indexes. By factor analysis, the 22 personality scales have been reduced to four personality factors, labeled as Dependability, Chinese Tradition, Social Potency, and Individualism (Table 1). Cheung et al. (1998) have studied the degree of overlap between CPAI and the Revised NEO Personality Inventory (Costa and McCrae, 1992) and the results show that the indigenously developed instrument broadens the definition of the personality sphere relative to the imported NEO-PI-R. It has been found that the unique dimension of personality from the CPAI is Chinese Tradition. Cheung et al., regard four of its facets - Ren Qing (Relationship Orientation), Flexibility, Harmony, and Face - as defining unique aspects of personality. These facets of Chinese Tradition have no counterparts in the NEO-PI-R and therefore would have been missed in operationalization of the personality sphere provided by the imported measure (Kwan and Bond, 1997).

The finding of a distinct indigenous factor of personality variation in Chinese populations raises some fascinating points. With respect to the Cheung et al. (1998) research, it is interesting to examine whether the distinctive facets of Chinese Tradition supplement the apparently universal Big Five or MBTI personality factors; and whether local constructs that are shown to be empirically distinct from relevant imported material add predictive power to the imported constructs.

\section{Indigenous Personality Constructs on the CPAI}

In the development of the CPAI, consideration was given to Chinese culture in general and to the specific socio-cultural contexts of the PRC and Hong Kong. The following are six personality constructs that were deemed to be of specific interest to Chinese culture, but that were not covered in most of the translated personality inventories (Cheung, 1996).

\section{Harmony}

Harmony measures one's inner peace of mind, contentment, as well as interpersonal harmony. The avoidance of conflict and maintenance of the equilibrium are considered virtues in Chinese culture. This aspect of social behavior has been discussed extensively by Chinese social psychologists in conjunction with studies in conflict avoidance and conflict resolution (Bond and Hwang, 1986; Bond and Wang, 1983).

\section{Renqing}

This is a more complicated social relationship concept in the Chinese culture. Hwang (1987) describes Renqing as social favors that are exchanged in the form of money, goods, information, status, service, and affection according to an implicit set of rules. However, this set of rules is dependent upon the category of social ties between the individuals involved in the interaction. In this sense, the Renqing scale measures the individual's adherence to cultural norms of interaction based on various standards of social exchange. The forms of interaction involve courteous rituals, exchange of resources, reciprocity, maintaining and utilizing useful ties, and nepotism.

\section{Ah-Q Mentality}

This consists of a pattern of defense mechanisms depicted in the caricature of $A h-Q$, a well-known fictional character in Chinese literature in the early 20th century, upon which 
the personality construct is based. Defense mechanisms include self-protective rationalizations, externalization of blame, self-enhancement, and belittling others' achievements. In the True Story of $A h-Q$ by Lu Hsun (Lu, 1976), the character of $A h-Q$ was meant to satirize the personality shortcomings of traditional Chinese people. To a certain extent, a mild degree of $A h-Q$ mentality is accepted as a protective mechanism against defeat and disappointment.

\section{Graciousness}

Graciousness is a Confucian virtue characterized by patience, forgiveness, acceptance of self and others, and self-sacrifice, as opposed to the mean and calculating characteristics of cynicism, vindictiveness, and negativism. This virtue resembles the values of patience, courtesy, and kindness found in the "human-heartedness" factor of Bond's Chinese Value Survey (Hofstede, 1991)

\section{Veraciousness-Slickness}

This is a personality dimension often used by Chinese people to judge the trustworthiness of a person. Veracious individuals are loyal and honest, keep their feet on the ground, work hard without pretense, uphold their principles, and sacrifice their personal interests for the group. However, people who are overly veracious may be inflexible and not able to adapt. On the other hand, slick people are not to be trusted because they tend to be too smooth and tactful, always try to please others, and would change their principles to fit their objectives.

\section{Face}

Face is a dominant concept in interpreting and regulating social behaviour in Chinese culture. Although the concept of Face has universal applicability (Ho, 1976) and has been defined by the Western sociologist Goffman (1955) as "an image of self delineated in terms of approved social attributes," Bond and Hwang (1986) point out that what constitutes a desirable Face is specific to the culture. In Chinese culture, the concept of Face is more interpersonally connected. The protection and enhancement of Face are "more disciplined by concerns about hierarchical order in Chinese culture" (p.249). In the CPAI, the Face Scale covers the concern for maintaining Face and social behaviours that enhance one's own Face and that avoid losing one's Face. Too much emphasis on Face, as in the case of slickness, will lead to superficiality.

\section{Methodology}

\section{Sample}

Data for the present study were collected from tutors and students on different courses offered by the Open University of Hong Kong. Form B of the Chinese Personality Assessment Inventory (CPAI), consists of 352 items, was sent to the 59 tutors who had completed and returned the MBTI in an earlier study (Chan, 2001), of which 57 were completed correctly, thus constituting a 96.6 per cent response rate. The same set of data obtained from 1,106 students with respect to their evaluation of tutors' teaching performance was also used for this paper. 


\section{Procedure}

As indicated in Chan (2001), 110 tutors were administered a self-rating personality instrument (the MBTI) at the start of a semester, and 59 tutors completed and returned the questionnaire. In addition, a teaching evaluation questionnaire was distributed to their students during a tutorial session by the end of the semester. In order to examine the difference, if any, when a different measure was used, all 59 tutors were administered the CPAI during the same semester. The same set of data on students' evaluation of tutors was also used. All response forms from tutors were returned directly to the researcher for scoring and report generation. The scoring was done with the use of a scoring syntax using SPSS programs.

Before completing the questionnaires, all participants were given formal written information regarding the purpose of the assessment process and the manner in which the feedback and personality results would be used. They were also instructed to be as open and honest in their ratings as possible. Tutors were assured that their preference scores would be reported only in aggregate form, and that their unique scoring would not be released to anyone, not even their course coordinator. The procedure was conducted in this manner to ensure the confidentiality of the assessments and thus to enhance rater motivation and the subsequent validity and utility of the feedback data collected. Although these conditions do not guarantee the absence of biases entering into the rating process, they do provide an acceptable level of confidence in the integrity and accuracy of the data obtained.

\section{Measures}

The CPAI was completed by tutors, and the Teaching Evaluation Questionnaire (TEQ) completed by their students in the earlier study (Chan, 2001), was again used for this study. As noted above, the CPAI is a personality measure developed by Cheung et al. (1996). It was chosen for classifying psychological type in this paper because it is a unique measure with scales that were deemed to be of specific pertinence to Chinese culture, but were not covered in imported personality inventories.

The TEQ was designed exclusively for Chan (2001) and the present study. It was based on a combination of prior behavioural research differentiating between the performance of teachers (Fernandez and Mateo, 1992; Gaski, 1987; Wagenaar, 1995). The opinions of tutors, students, as well as expert colleagues, were also sought in the design of the questions. The instrument contains twenty-seven items pertaining to various aspects of teaching behaviour, including fifteen items designed to evaluate tutors' teaching strategies/ styles that ranges from highly controlling to highly autonomous and supportive. For each item, respondents were asked to rate their tutor using a scale from 1 to 5 (where 1 = almost never and 5 = almost always) on the degree to which that tutor engaged in a given behavioural practice, such as:

- Praises students for good ideas or useful contributions

- Welcomes imagination, creativity and new ideas

- Stimulates students to think independently

- Communicates the purpose of each class session and learning activity

- Presents ideas in an interesting way

- Shows enthusiasm in teaching; treats students with respect

- Manages classroom discussions so that they are a useful part of learning experiences 
Chan - A Study of the Relationship Between Tutor's Personality and Teaching Effectiveness

- Acts as a member of the group rather than an autocratic leader, etc.

\section{Results and Discussion}

The result obtained from a principal components factor analysis on the behavioural ratings student data is shown in Table 2, which summarises result of the factor analysis of the TEQ. It yielded four independent and distinct dimensions of teaching effectiveness (all with eigenvalues greater than 1.0). Based on the item content, these factors were labeled as: motivation, presentation, attitude, and interaction. The fifteen items designed for testing degree of autonomy-supportiveness were found to belong to subscales of 'motivation' and 'interaction' respectively. Overall, this four-factor solution accounted for 58.1 per cent of the total variance in behaviour ratings, with the largest portion (43.3 per cent of the variance) represented by the motivation factor. This finding, in and of itself, highlights the singular importance of autonomy-supportive dimension involved in the evaluation of teaching effectiveness within the context of distance education - the support of students' initiatives and intrinsic motivation is of vital importance.

Subscales were calculated for each of these factors for further analysis. Calculated reliability quotients were all within an acceptable range (.78 to .87). Next, item analysis using the reliability analysis procedure was carried out to decide which items to exclude from each sub-scale. Two items were deleted from subscale of 'motivation' and one from 'presentation.' Reliability quotients increased and fall within the range .78 to .91.

An independent sample t-test was carried out to evaluate the difference between the means of the four subscales and each of the 22 personality dimensions. As teaching effectiveness can be affected by various independent factors other than personality, such as tutor's age, gender and cultural background, a $p$ value less than 0.10 was adopted as a criterion in this study. The result indicated that four personality dimensions are significantly related to tutors' teaching performance: Renqing, Face, Harmony and Leadership (see Table 3). Each personality type, however, contributes to make to the effectiveness of the tutorial process. Obviously, this does not imply that other factors were not important. Each is discussed as follows:

\section{Renqing}

The result shows that tutors with high score on Renqing were evaluated by their students as significantly better than those less concerned about Renqing in terms of motivation, presentation and attitude $(t=1.963, p<.1 ; t=1.869, p<.1$; and $t=2.209, p<.05$ respectively).

Renqing is one of the commonly accepted social norms regulating Chinese interpersonal relationships, and it has three different meanings in Chinese culture (Hwang, 1987). First, it indicates the emotional responses of an individual confronting the various situations of daily life. In this sense, Renqing is closely related to the Confucian concept of behavioral propriety, which stresses the social responsibility of individuals to be aware of and behave according to certain prescribed rules of behaviour. If an individual can understand other people's emotional responses to various life circumstances, then such a person is well versed in Renqing. If a person is accused of "understanding no Renqing," it means that this person is incapable of managing interpersonal relationships. Renqing is a kind of favour with the inclusion of a sentimental element. It can be interpreted as "human feelings" which covers not only sentiment but also its social expressions such as the offering of congratulations or showing of sympathy. Such expressions are likely to be 
associated with perceptions of being supportive and friendly. Accordingly, it is not surprising to find that tutors who rank highly on Renqing, were perceived by students as better than those less concerned with Renqing in terms of motivation and attitude.

Second, Renqing is a resource that an individual can present to another person as a gift during the course of social exchange.

Third, Renqing connotes a set of social norms by which one has to abide in order to get along well with other people in Chinese society. This norm includes two basic social behaviours: 1) one should keep in contact with the acquaintances in one's social network; and 2) when a member of one's network gets into trouble or faces a difficult situation, one should sympathize, offer help, and "do a Renqing” for that person. In this sense, Renqing is closely intertwined with guanxi. Since Renqing involves social exchanges, there is an inherent obligation for people to keep equity in mind. For example, it will be highly possible for this tutor to entertain students' request for extension in submitting assignments, and he or she would tend to be patient in dealing with students'queries, clarifying misconceptions, etc. Having rendered such a Renqing to a student, the tutor may, however, also expect to receive in reciprocity, a positive evaluation from student that can boost his or her reputation. Therefore, Renqing is best translated as 'humanized obligation,' which implies that a continued favor exchange with a sentimental touch is involved.

Cross-cultural research has shown that, in comparison with their American counterparts, Chinese subjects tend to be more collectivist in contrast to the general individualistic orientation of Americans (Hofstede, 1980). Research also indicates that Chinese are bound by the social obligation to help others who need help in the social group to which they belong (Huang and Harris, 1974). Hwang (1987) suggests that in Chinese society, many people like to make the best of the special qualities of the mixed tie by cutting a figure of power in order to impress others. This, they hope, will place them in a favourable position for any future allocation of some others' resources. Thus the person who allocates resources (the tutor in this case) has to take the rule of Renqing into account whenever he or she is asked to distribute a resource in a beneficial way to any other individual sharing the same 'network.'

\section{Face}

Tutors that rated high on Face were evaluated by their students as significantly better than those less concerned about Face in terms of their attitude of teaching $(t=1.988, p<.10)$.

Face is an individual's public image, gained by performing one or more specific social roles that are well organized by others (Tsang, 1998). The concept of Face and its role in social interactions has been extensively studied since Goffman's $(1955,1956)$ pioneering work. Goffman (1955) conceptualized Face as "the positive social value a person effectively claims for himself by the line others assume he has taken during a particular contact.”

Face is another key element in the development and maintenance of guanxi. According to $\mathrm{Hu}$ (1944), there are two dimensions to the Chinese concept of Face: Lien and Mien-tzu. Lien is good moral character, and carries with it the idea of one being a 'decent human being.' It is more ascribed than achieved. Mien-tzu, as well as meaning the Face physiologically, carries with it the idea of reputation based on one's own efforts. Mien$t z u$ is considered useful but not essential to life and is more achieved than ascribed. 
The concept of Face refers to one's ability to deal smoothly with people. Face-to-Face one's generosity and actions are taken to enhance one's personal prestige and/ or that of their family and social associates (Brunner and Wang, 1989). Face can be gradually increased by personal endeavor such as hard work, political status or connections, personal services benefiting society, superior intellectual knowledge, or skillful negotiating. It can also be borrowed from others, and enhanced by the accumulation of wealth, a good reputation, and exemplary behaviour.

The nature of Face interaction is interdependent (Kim and Nam, 1998). Each participant is responsible for saving both their own Face and the other's Face. Chinese children are inculcated with the concept of Face and therefore develop an internalized sense of appropriate behaviour. One's Face is also closely associated with their status in society. The higher one's social or political standing, the more dignity one has to maintain, and those who have more power are expected to adhere to a higher code of ethics than those of lesser standing. Further, one who is well educated is expected to maintain more selfcontrol in social activities then those who are not as well educated. Those who are better educated are expected to control their emotions and not to engage in arguments with those on lower social levels. Tutors at the Open University of Hong Kong have at minimum a Bachelor degree and many, in fact, work at managerial levels within their work organizations. This explains why tutors who rank high on Face scale are perceived as having good attitudes in teaching. As leaders of a group of adult students, they may feel too self-conscious to behave in a friendly and helpful way and also uphold the level of respect from students.

In Chinese culture, many individuals are highly conscious of their responsibility for developing their character according to the demands of their status in society. Moreover, many are acutely aware that any disregard of these standards of behaviour will result in their associates questioning their moral character and doubting their ability to perform their role in society. This 'loss of Face' could conceivably isolate them from those with whom they function and result in such deep feelings of insecurity that they would be unable to function effectively (Brunner and Wang, 1989). Tutors ranking high on Face, tend to be concerned about students' opinion of them, and their attitude towards them. They are not ready to discuss their weaknesses, even with their closest friends. Hence they may feel a loss of Face when they cannot answer students' queries. A tutor high on Face, therefore, may strive to protect himself or herself from losing Face in tutorials. Often tutors may achieve this by working hard, and being well prepared and organized for their tutorial sessions.

Traditional Chinese cherish hierarchical status in social relations (Hwang, 1987). As noted earlier, the Face Scale in the CPAI covers the concern for maintaining Face and social behaviors that enhance one's own Face and that avoid losing one's Face. An individual's social connections are important factors that are frequently taken into consideration by others in judging overall social status. Within a social network, having Face enhances not only relative position, but also bestows many kinds of privileges that further improve the quality of life. This being so, saving Face rather than losing it becomes a primary objective in Chinese society. When one is subjectively suffering loss of Face, one's self-esteem is injured, resulting in emotional uneasiness. Thus, in addition to maintaining Face, one must utilize every sort of Face work to 'earn' Face. Some common strategies of saving Face for another include: avoiding criticizing anyone in public, using circumlocution and equivocation in any criticism of another's performance, and according greater social rewards to those skilled at preserving Face for others. Chinese use all these strategies frequently in managing a modern social organization (Silin, 1976). Tutors may also adopt these strategies when they conduct tutorials in order 
to earn Face and save others' Face. These strategies help bring about harmony, which is discussed in the following section.

\section{Harmony}

Tutors ranking high on Harmony were evaluated by their students as being significantly better than those less concerned about Harmony in terms of motivation, presentation, attitude and interaction $(t=3.848, p<.05 ; t=3.347, p<.05 ; t=3.934, p<.05$; and $t=$ $2.595, p<.05$ respectively).

Harmony is a deeply embedded social value in Chinese culture, emphasized in the dominant religious and philosophical traditions - Confucianism, Taoism and Buddhism. It refers to the balance achieved in relationships (Kwan and Bond, 1997). The major focus of this concept is on the relationship, rather than on the satisfaction of its constituent individuals or support derived by an individual from that relationship. Chinese people pursue harmony in their relationships with nature, self, and other individuals (Lee, 1995). One of the characteristics of a culturally salient 'socialorientation' personality is that Chinese people can sacrifice their own interests and suppress their own desires to achieve and maintain harmonious relations with other people (Leung and $\mathrm{Wu}, 1996)$. The importance of harmony is highly related to cultural values such as Face and reciprocity. Chinese traditions stress harmony between people and their environment, intra-personal harmony and, of most significance here, harmony in social relationships. Harmony is not a central construct in Western ideology where dominant value orientations are based upon notions of equality, egalitarianism, and consensus (Westwood, 1997). Chinese tend to discourage and inhibit aggressive outbursts in order to maintain interpersonal harmony within their group (Bond and Wang, 1983).

Tutors with a high concern for Harmony will tend to conduct tutorials so as to maintain proper harmony, both within the group and between themselves and other members. Tutors are prone to subordinate personal needs to those of the group, to accept the group's norms rather than insisting on their personal norms. Harmony therefore, is more important than, for example, broadcasting one's personal notion of truth. They tend to believe harmony helps foster sentiments of solidarity and that it consolidates beneficial bonds of mutual obligation and reciprocity. An interesting point to note in this study is that all 22 tutors with a high score on Harmony also score highly on Face and Renqing. As noted earlier, a tutor well versed in Renqing is likely to express friendship and sympathy, in the hope that harmony within the group is maintained through gracious reciprocity of help. A tutor scoring high on Face is also concerned about earning face as well as saving student's face - in the latter case, the tutor is obviously adopting conflict avoidance strategies in the hope of bringing harmony in classes.

\section{Leadership}

Tutors ranking high on Leadership were evaluated by their students as significantly better than those less concerned about Leadership in terms of motivation, interaction and presentation ( $t=2.528, p<.05 ; t=2.401, p<.05$; and $t=1.758, p<.1$ respectively).

Whilst Renqing, Face, and Harmony are three dimensions on the Chinese Tradition factor of the CPAI, Leadership is not of specific interest to the Chinese culture. Nonetheless, it can be easily comprehended why Leadership is crucial to teaching, and will not be discussed in detail in this paper. Apart from possessing excellent presentation skills, an effective tutor should be able to lead discussions and debates, as well as encourage small 
group interactions. As leader of a tutorial group, tutors must be able to facilitate student independence and foster students' critical thinking and self-directed learning. In doing so, they have to guide the students in their thinking, thereby stimulating them to be reflective thinkers. Therefore, tutors who are eager to become a leader of a group are likely to be more effective in presentation as well as in motivating and interacting with students.

\section{Conclusions}

This study reveals that Renqing, Face, Harmony and Leadership significantly predict tutors' teaching effectiveness in the classroom environment. Certain facets from the distinctive indigenous factor of Chinese Tradition seem to be a useful complement to MBTI in predicting Chinese teaching attitudes and behavior. In particular, Harmony seems to be significantly related to all four dimensions of teaching.

As the Chinese are relation-orientated people, they are naturally preoccupied with guanxi construction. Whilst the concepts of Face, Renqing and Harmony are very different from each other, they all interrelate. They depict the emphasis on implicit rules of interpersonal dynamics within Chinese culture. A tutor scoring high on Renqing may tend to give Face to students participating in tutorials, with the underlying aim of maintaining a harmonious relationship with each other.

The major aim of Confucianism is to achieve social harmony, which depends not only on the maintenance of correct relationships among individuals, but also on the protection of an individual's Face or one's dignity, self-respect, and prestige. Social interactions should be conducted so that nobody's Face is lost. If one does not have Face, one has limited social resources to use in cultivating and developing one's connection network. Therefore, one has to have Face in order to build one's own network. Normally, a teacher is regarded as one who holds higher social position and has greater Face. In the Chinese art of relationship management, Renqing also plays an important role; it is a crucial vehicle in Chinese social exchanges. In general, Renqing and Face represent some kind of social capital or resource in interpersonal exchanges.

This paper suggests that imported personality instruments may not necessarily be comprehensive enough to reveal particular distinctive factors in specific cultures. As shown in this case, some scales on the Chinese Tradition factor may have important contributions to make in the predictive role of personality measures. The uniqueness of the Chinese Tradition factor has been confirmed in a number of follow-up studies. The Chinese Tradition factor was found to stand apart from the five-factor structure (Goldberg, 1990; McCrae and Costa, 1997) when both the CPAI and the NEO Personality Inventory, which measures the Big Five, were used (Cheung et al., 1998; Sun, 1997; Zhang and Bond, 1998). Such research with the indigenous constructs identified in the CPAI points to the inadequacy of existing personality theories and instruments in covering all the relevant domains of Chinese personality. As it could be shown that the MBTI could not subsume all the CPAI scales, it may be challenged that this model is incomplete.

Certain scales on the Chinese Tradition factor of the CPAI have been shown to be relevant in predicting Chinese tutors' behavior. Yet it remains uncertain as to whether this Chinese Tradition factor is unique to the Chinese culture or whether it is also comprises part of a universal domain useful in understanding key interpersonal aspects of personality that have been inadvertently overlooked by psychologists who rely solely on Western personality inventories. Future research with the CPAI involving cross-cultural samples may provide answers to this. 
Table 1. Categorization of the 22 Personality Dimensions on the CPAI

\begin{tabular}{|c|c|c|c|c|}
\hline & Dependability & Chinese Tradition & Social Potency & Individualism \\
\hline 1. Self $\mathrm{v}$. social orientation & & & & $\sqrt{1}$ \\
\hline 2. Graciousness v. meanness & $\sqrt{1}$ & & & \\
\hline 3. Introversion-Extroversion & & & $\sqrt{1}$ & \\
\hline 4. Harmony & & $\sqrt{1}$ & & \\
\hline 5. Leadership & & & $\sqrt{1}$ & \\
\hline 6. Face & $\sqrt{ }$ & & & \\
\hline $\begin{array}{l}\text { 7. Ren Qing (Relationship) } \\
\text { Orientation }\end{array}$ & & $\sqrt{1}$ & & \\
\hline 8. Family Orientation & $\sqrt{ }$ & & & \\
\hline 9. Optimism-Pessimism & $\sqrt{ }$ & & & \\
\hline 10. Flexibility & & $\sqrt{1}$ & & \\
\hline $\begin{array}{l}\text { 11. Logical vs. Affective } \\
\text { Orientation }\end{array}$ & & & & $\sqrt{1}$ \\
\hline 12. Modernization & & $\sqrt{1}$ & & \\
\hline 13. Emotionality & $\sqrt{ }$ & & & \\
\hline 14. Thrift-Extravagance & & $\sqrt{1}$ & & \\
\hline 15. Responsibility & $\sqrt{ }$ & & & \\
\hline 16. Adventurousness & & & $\sqrt{1}$ & \\
\hline 17. Meticulousness & $\sqrt{1}$ & & & \\
\hline 18. Defensiveness & & & & $\sqrt{1}$ \\
\hline 19. Veraciousness-Slickness & $\sqrt{ }$ & & & \\
\hline 20. Practical Mindedness & $\sqrt{1}$ & & & \\
\hline $\begin{array}{l}\text { 21. External vs. Internal } \\
\text { Locus of Control }\end{array}$ & $\sqrt{ }$ & & & \\
\hline $\begin{array}{l}\text { 22. Inferiority vs. Self- } \\
\text { Acceptance }\end{array}$ & $\sqrt{1}$ & & & \\
\hline
\end{tabular}


Table 2. Total variance explained

\begin{tabular}{|c|c|c|c|c|c|c|}
\hline \multirow[b]{2}{*}{ Component } & \multicolumn{3}{|c|}{ Initial Eigenvalues } & \multicolumn{3}{|c|}{ Extraction Sums of Sơuared Loadings } \\
\hline & Total & $\%$ of Variance & $\begin{array}{c}\text { Cumulative } \\
\%\end{array}$ & Total & $\%$ of Variance & $\underset{\%}{\text { Cumulative }}$ \\
\hline 1 & 11695 & 43.316 & 43.316 & 11695 & 43.316 & 43.316 \\
\hline 2 & 1.722 & 6377 & 49.698 & 1.722 & 6.377 & 49.698 \\
\hline 3 & 1251 & 4634 & 54.327 & 1251 & 4634 & 54.327 \\
\hline 4 & 1.029 & 3810 & 58.137 & 1.029 & 3810 & 58.137 \\
\hline 5 & .920 & 3.407 & 61.544 & & & \\
\hline 6 & .80 & 3261 & 64.805 & & & \\
\hline 7 & .817 & 3.027 & 67.832 & & & \\
\hline 8 & .728 & 2.697 & 70.529 & & & \\
\hline 9 & .676 & 2.503 & 73.003 & & & \\
\hline 10 & .617 & 2286 & 75.319 & & & \\
\hline 11 & .563 & 2.046 & 77.366 & & & \\
\hline 12 & .528 & 1956 & 79.321 & & & \\
\hline 13 & .514 & 1.903 & 81.224 & & & \\
\hline 14 & .496 & 1836 & 83.061 & & & \\
\hline 15 & .478 & 1.771 & 84.832 & & & \\
\hline 16 & .454 & 1.681 & 86.513 & & & \\
\hline 17 & .429 & 1.590 & 88.103 & & & \\
\hline 18 & .405 & 1501 & 89.604 & & & \\
\hline 19 & .379 & 1.400 & 91.007 & & & \\
\hline 20 & .360 & 1333 & 92.340 & & & \\
\hline 21 & .348 & 1290 & 93.600 & & & \\
\hline 22 & .309 & 1.143 & 94.773 & & & \\
\hline 23 & .302 & 1.118 & 95.891 & & & \\
\hline 24 & .287 & 1.064 & 96.965 & & & \\
\hline 25 & .284 & 1.052 & 98.007 & & & \\
\hline 26 & .274 & 1.016 & 99.023 & & & \\
\hline 27 & .264 & .977 & 100,000 & & & \\
\hline
\end{tabular}


Table 3(a). t-test Analysis between High-Face(H) and Low-Face(L) Groups on the Four Teaching Dimensions

\begin{tabular}{|c|c|c|c|c|c|c|}
\hline & FACE & N & Mean & Std. Deviation & $t$ & sigrificance \\
\hline \multirow{2}{*}{ Motivation } & $\mathrm{H}$ & 34 & 40000 & .3023 & \multirow{2}{*}{.229} & .820 \\
\hline & L & 23 & 39800 & .2292 & & \\
\hline \multirow{2}{*}{ Presentation } & $\mathrm{H}$ & 34 & 3.5143 & .3340 & \multirow[t]{2}{*}{.807} & .423 \\
\hline & L & 23 & 3.4448 & .2947 & & \\
\hline \multirow{2}{*}{ Attitude } & $\mathrm{H}$ & 34 & 3.4392 & .3955 & \multirow[t]{2}{*}{1988} & $.052^{x}$ \\
\hline & L & 23 & 32281 & .3900 & & \\
\hline \multirow{2}{*}{ Interaction } & H & 34 & 3.7210 & .3998 & \multirow{2}{*}{.014} & .989 \\
\hline & L & 23 & 3.7223 & .3147 & & \\
\hline
\end{tabular}

$* p<0.10$

Table 3(b). t-test Analysis between High-Leadership (H) and Low-Leadership (L) Groups on the Four Teaching Dimensions

\begin{tabular}{|c|c|c|c|c|c|c|}
\hline & FACE & $N$ & Mean & Std. Deviation & $t$ & sigrificanoe \\
\hline \multirow{2}{*}{ Motivation } & H & 19 & 4.1167 & .2179 & \multirow{2}{*}{2528} & $.014^{\pi}$ \\
\hline & L & 38 & 39314 & .2798 & & \\
\hline \multirow{2}{*}{ Presentation } & H & 19 & 35891 & .2724 & \multirow[t]{2}{*}{1.758} & $.084^{\circ}$ \\
\hline & L & 38 & 3.4349 & .3297 & & \\
\hline \multirow{2}{*}{ Attitude } & $\mathrm{H}$ & 19 & 33560 &.$\$ 16$ & \multirow[t]{2}{*}{.$\infty 37$} & .971 \\
\hline & L & 38 & 3,3526 & .4191 & & \\
\hline \multirow{2}{*}{ Interaction } & H & 19 & 38790 & .2363 & \multirow[t]{2}{*}{2.401} & $.020^{2 x}$ \\
\hline & L & 38 & 3.6428 & .3939 & & \\
\hline
\end{tabular}

$* p<0.10$

$* * p<0.05$ 
Table 3(c). t-test Analysis between High-Renqing(H) and Low-Renqing(L) Groups on the Four Teaching Dimensions

\begin{tabular}{|c|c|c|c|c|c|c|}
\hline & RENQING & $N$ & Mean & Std. Deviation & $t$ & sigrificanoe \\
\hline \multirow{2}{*}{ Motivation } & $\mathrm{H}$ & 24 & 40743 & .2502 & \multirow[t]{2}{*}{1963} & \multirow[t]{2}{*}{$.055^{\circ}$} \\
\hline & L & 33 & 39341 & .2774 & & \\
\hline \multirow{2}{*}{ Presentation } & $\mathrm{H}$ & 24 & 3.5765 & .3376 & \multirow[t]{2}{*}{1869} & \multirow[t]{2}{*}{$.06 \%^{\pi}$} \\
\hline & L & 33 & 3.4206 & .2905 & & \\
\hline \multirow{2}{*}{ Attitude } & $\mathrm{H}$ & 24 & 3.4800 & .4638 & \multirow[t]{2}{*}{2209} & \multirow[t]{2}{*}{$.031^{x \pi}$} \\
\hline & L & 33 & 32567 & .3274 & & \\
\hline \multirow{2}{*}{ Interaction } & $\mathrm{H}$ & 24 & 3.7988 & .4174 & \multirow[t]{2}{*}{1374} & .175 \\
\hline & $\mathrm{L}$ & 33 & 3.6653 & .3161 & & \\
\hline \multicolumn{7}{|l|}{$* p<0.10$} \\
\hline
\end{tabular}

Table 3(d). t-test Analysis between High-Harmony(H) and Low-Harmony(L) Groups on the Four Teaching Dimensions

\begin{tabular}{|c|c|c|c|c|c|c|}
\hline & RENQING & $N$ & Mean & Std. Deviation & $t$ & sigrificance \\
\hline \multirow{2}{*}{ Motivation } & H & 22 & 4.1504 & .2801 & \multirow[t]{2}{*}{3848} & \multirow[t]{2}{*}{$.000^{\mathrm{\alpha x}}$} \\
\hline & L & 35 & 38943 & .2197 & & \\
\hline \multirow{2}{*}{ Presentation } & H & 22 & 3.6497 & .3454 & \multirow{2}{*}{3347} & \multirow{2}{*}{$.001^{x x}$} \\
\hline & L & 35 & 3.3805 & .2542 & & \\
\hline \multirow{2}{*}{ Attitude } & H & 22 & 3.5905 & .4248 & \multirow[t]{2}{*}{3934} & \multirow[t]{2}{*}{$.000^{\mathrm{xx}}$} \\
\hline & L & 35 & 32054 & .3129 & & \\
\hline \multirow{2}{*}{ Intersction } & H & 22 & 38722 & .4529 & \multirow[t]{2}{*}{2595} & \multirow[t]{2}{*}{$.012^{\mathrm{xx}}$} \\
\hline & L & 35 & 3.6268 & .2619 & & \\
\hline
\end{tabular}

$* * p<0.05$ 
Chan - A Study of the Relationship Between Tutor's Personality and Teaching Effectiveness

\section{References}

Amabile, T. M. (1979). Effects of External Evaluations on Artistic Creativity. Journal of Personality and Social Psychology, 37, 221 - 233.

Barrett, L. A. (1991). Relationship of Observable Teaching Effectiveness Behaviours to MBTI Personality Types, Paper Presented at the Ninth International Conference of the Association for Psychological Type, Richmond, Virginia.

Barrows, H. S. (1992). The Tutorial Process. Springfield: Southern Illinois University of Medicine.

Beaudoin, M. (1990). The Instructor's Changing Role in Distance Education. The American Journal of Distance Education 4(2), 21 - 29.

Benware, C., and Deci, E. L. (1984). The Quality of Teaching with an Active Versus Passive Motivational Set. American Educational Research Journal 21, 755 765.

Boggiano, A. K., Flink, C., Shields, A., Seelbach, A., and Barrett, M. (1993). Use of Techniques Promoting Students' Self-Determination: Effects of students' analytic problem-solving skills. Motivation and Emotion 17, 319 - 336.

Bond, M. H. (2000). Localizing the Imperial Outreach. American Behavioral Scientist 44(1), $63-72$.

Bond, M. H. and Hwang, K. K. (1986). The Social Psychology of Chinese People. In M. H. Bond (Ed.) The Psychology of the Chinese People. (p. 213-266). HK: Oxford University Press.

Bond, M. H., and S. H. Wang (1983). Aggressive Behaviour in Chinese Society: The problem of maintaining harmony. In A. P. Goldstein and M. Segall (Eds.) Global Perspectives on Aggression. New York: Pergamon, 58 - 74.

Brunner, J. A., and Wang, Y. (1989). Chinese Negotiating and the Concept of Face. Journal of International Consumer Marketing 1(1), 27 - 43.

Chan, B (2001). An Empirical Study of the Relationship Between Tutor's Personality and Teaching Effectiveness: Implications for Management of Tutors in Distance Education. International Conference on Offshore Education and Training in an e-Learning World, Australia.

Cheung, F. M. (1996). Development of the Chinese Personality Assessment Inventory. Journal of Cross Cultural Psychology 27(2), 181 - 199.

Cheung, F. M., and Leung, K. (1998). Indigenous Personality Measures: Chinese Examples. Journal of Cross-Cultural Psychology 29(1), 233 - 248.

Cheung, F. M., Leung, K., Zhang, J. X., Sun, H. F., Gan, Y. Q., Song, W. Z., and Xie, D. (1998). Indigenous Chinese Personality Constructs: Is the Five Factor Model Complete? Manuscript submitted for publication. Cited in M. H. Bond (2000) Localizing the Imperial Outreach, American Behavioral Scientist 44(1), 63 - 72. 
Church, A. T. (1987). Personality Research in a Non-Western Culture: The Philippines. Psychological Bulletin 102, 272 - 292.

Costa, P. T. Jr., and McCrae, R. R. (1992). Revised NEO Personality Inventory (NEO-PI$R$ ) and NEO Five-Factor Inventory (NEO-FFI) Professional Manual. Odessa, FL.: Psychological Assessment Resources.

deCharms, R. (1976). Enhancing Motivation: Change in the Classroom. New York: Irvington.

Deci, E. L., Schwartz, A., Sheinman, L. and Ryan, R. M. (1981a). An Instrument to Assess Adult's Orientations Toward Control Versus Autonomy in Children: Reflections on Intrinsic Motivation and Perceived Competence. Journal of Educational Psychology 73, 642 - 650.

Deci, E. L., Nezlek, J., and Sheinman, L. (1981b). Characteristics of the Rewarder and Intrinsic Motivation of the Rewardee. Journal of Personality and Social Psychology 40, $1-10$.

Deci, E. L., and Ryan, R. M. (1987). The Support of Autonomy and the Control of Behaviour. Journal of Personality and Social Psychology 53, 1024 - 1037.

Deci, E. L., Vallerand, R. J., Pelletier L. G., and Ryan, R. M. (1991). Motivation and Education: The Self-Determination Perspective. Educational Psychologist 26, $325-346$.

Fernandez, J., and Mateo, M. A. (1992) Student Evaluation of University Teaching Quality: Analysis of a Questionnaire for a Sample of University Students in Spain, Educational and Psychological Measurement 52(3), 675 - 686.

Fisher, D. L., and Kent, H. B. (1998) Associations Between Teacher Personality and Classroom Environment, Journal of Classroom Interaction 33(1), 5 - 13.

Flink, C., Boggiano, A. K., Main, D. S., Barrett, M., and Katz, P. A. (1992). Children’s Achievement-Related Behaviours: The role of extrinsic and intrinsic motivational orientations. In A. K. Boggiano and T. S. Pittman (Eds.) Achievement and Motivation: A Social-Developmental Perspective (p. 189-214). New York: Cambridge University Press.

Gaski, J. (1987). On Construct Validity of Measures of College Teaching Effectiveness, Journal of Educational Psychology 73(3), 326 - 330.

Goffman, E. (1955). On Face-Work: An analysis of ritual elements in social interaction, Psychiatry 18, $213-231$.

Goffman, E. (1956). Embarrassment and Social Organisation. American Journal of Psychology 62, $264-271$.

Goldberg, L. (1990). An Alternative "Description of Personality" The Big Five Factor Structure. Journal of Personality and Social Psychology, 59, 1216 - 1229. 
Grolnick, W. S., and Ryan, R. M. (1987). Autonomy in Children's Learning: An experimental and individual difference investigation. Journal of Personality and Social Psychology, 52, 890 - 898.

Hamza, K., and Nash, W. R. (1996). Creating and Fostering a Learning Environment That Promotes Creative Thinking and Problem Solving Skills. Research Report. ERIC Document ED 406435.

Harper, G., and Kember, D. (1986). Approaches to Study of Distance Education Students. British Journal of Educational Technology 17(3), 212 - 222.

Ho, D.Y. F. (1976). On the Concept of Face. American Journal of Sociology 81, 867 884.

Hofstede, G. (1991). Culture and Organisations: Software of the mind. New York: McGraw-Hill.

Hu, H. C. (1944). The Chinese Concepts of Face. American Anthropologist 46, 45 - 64.

Huang, L. C., and M. B. Harris (1974). Altruism and Imitation in Chinese and Americans: A Cross-Cultural Experiment. Journal of Social Psychology 93, 193 $-195$.

Hwang, K. K. (1987). Face and Favor: The Chinese power game. American Journal of Sociology, 92(4), $944-974$.

Kagan, D. M., and Grandgenett, D. J. (1987). Personality and Interaction Analysis, Studies in Higher Education 14, 13 - 24.

Kim, J. Y., and Nam, S. H. (1998). The Concept and Dynamics of Face: Implications for organizational behaviour in Asia. Organization Science, 9(4), 522 - 535.

Koestner, R., Ryan, R. M., Bernieri, F., and Holt, K. (1984). Setting Limits on Children's Behaviour: The differential effects of controlling versus informational styles on intrinsic motivation and creativity. Journal of Personality 52, 233 - 248.

Kwan, V. S. Y., and Bond, M. H. (1997). Pancultural Explanations for Life Satisfaction: Adding relationship harmony to self-esteem. Journal of Personality and Social Psychology, 73(5), 1038 - 1051.

Lee, Y. Y. (1995). The Chinese Traditional View of the Universe and Modern Business Behavior, In J. Qiao, and Y. G. Pan (Eds.) Chinese Conception and Behavior. TianJin: TianJin People Press.

Leung, K., and Wu, P. G. (1996). The Dual Role of "Harmony” in Management. Paper presented in the Conference of Organization and Management of Chinese Business. Taiwan University: Taipei.

Leung, K., and Zhang, J. X. (1995). Systemic Considerations: Factors facilitating and impeding the development of psychology in developing countries. International Journal of Psychology, 30, 693 - 706. 
Lorentz, J. L., and Coker, H. (1977). Myers-Briggs Types as Predictors of Observed Teacher Behaviour. Paper Presented at Second National Conference on the Use of the MBTI, Michigan State University, East Lansing.

Lu, H. (1976). The True Story of Ah-Q. HK: C\&W.

McCrae, R. R., and Costa, P. T. Jr. (1997). Personality Trait Structure as a Human Universal. American Psychologist 52, 509 - 516.

Patrick, B. C., Skinner, E. A., and Connell, J. P. (1993). What Motivates Children's Behaviour and Emotion? Joint effects of perceived control and autonomy in the academic domain. Journal of Personality 65, 781 - 791.

Pittman, T. S., Emery, J., and Boggiano, A. K. (1982). Intrinsic and Extrinsic Motivational Orientations: Reward induced changes in preferences for complexity. Journal of Personality and Social Psychology 42, 789 - 797.

Reeve, J. (1996). Motivating Others: Nurturing inner motivational resources. Boston, MA: Allyn and Bacon.

Reeve, J. (1998). Autonomy Support As An Interpersonal Motivating Style: Is It Teachable? Contemporary Educational Psychology 23, 312 - 330.

Ryan, R. M., and Connell, J. P. (1989). Perceived Locus of Causality and Internalization: Examining Reasons for Acting in Two Domains. Journal of Personality and Social Psychology 57, 749 - 761.

Ryan, R. M., and Grolnick, W. S. (1986). Origins and Pawns in the Classroom: SelfReport and Projective Assessment of Individual Differences in Children's Perceptions. Journal of Personality and Social Psychology 45, 736 - 750.

Shapira, A. (1976). Expectancy Determinants of Intrinsically Motivated Behaviour. Journal of Personality and Social Psychology 34, 1235 - 1244.

Silin, R. (1976). Leadership and Values: The organisation of large-scale Taiwanese enterprises. Cambridge, MA.: Harvard University Press.

Sun, H. F. (1997). Choice of Influence Tactics in Chinese Organizations: The effect of the interactants' personality and status. Unpublished Doctoral Dissertation. University of Hong Kong (In Chinese).

Tonelson, S. W. (1981). The Importance of Teacher Self-Concept to Create a Healthy Psychological Environment for Learning. Education 102, 96 - 100.

Tsang, E. W. K. (1998). Can Guanxi be a Source of Sustained Competitive Advantage for Doing Business in China? Academy of Management Executive 12(2), 64 - 73.

Vallerand, R. J., Fortier, M. S., and Guay, F. (1997). Self-Determination and Persistence in a Real-Life Setting: Toward a motivational model of high school dropout. Journal of Personality and Social Psychology 72, 1161 - 1176. 
Wagenaar, T. C. (1995) Student Evaluation of Teaching: Some Cautions and Suggestions, Teaching Sociology 23, pp.64-68.

Watkins, D. (1983). Only Rote Learning Needed at ANU, ANU Reporter, 14(16), 3.

Watkins, D., and Hattie, J. (1981). The Learning Processes of Australian University Students: Investigation of contextual and personological factors. British Journal of Educational Psychology 51, 384 - 393.

Westwood, R. (1997). Harmony and Patriarchy: The cultural basis for 'Paternalistic Headship’ among the overseas Chinese. Organization Studies 18(3), 445 - 480.

Williams, G. C., Weiner, M. W., Markakis, K. M., Reeve, J., and Deci, E. L. (1994). Medical Students' Motivation for Internal Medicine. Journal of General Internal Medicine, 9, 327 - 333.

Zhang, J. X., and Bond, M. H. (1998). Personality and Filial Piety Among Colleg Students in Two Chinese Societies. Journal of Cross-Cultural Psychology, 29(3), $402-417$.

\section{Athabasca}

